\title{
Aurora $A$ is differentially expressed and regulated in chromosomal and microsatellite instable sporadic colorectal cancers
}

\author{
Silke Lassmann ${ }^{1}$, Mihai Danciu ${ }^{1,2}$, Matthias Müller ${ }^{1}$, Roland Weis ${ }^{1}$, Frank Makowiec ${ }^{3}$, \\ Jürgen Schulte-Mönting ${ }^{4}$, Ulrich T Hopt ${ }^{3}$ and Martin Werner ${ }^{1}$ \\ ${ }^{1}$ Institute of Pathology, University Medical Center, Albert-Ludwigs University, Freiburg, Germany; ${ }^{2}$ Pathology \\ Department, Faculty of Medicine, University of Medicine and Pharmacy, 'Gr T Popa', Iasi, Romania; \\ ${ }^{3}$ Department of Surgery, University Medical Center, Albert-Ludwigs University, Freiburg, Germany and \\ ${ }^{4}$ Institute for Medical Biometry and Informatics, University Medical Center, Albert-Ludwigs University, \\ Freiburg, Germany
}

\begin{abstract}
The centrosome-associated kinase aurora $A$ has been shown to be involved in genetic instability and to be (over)expressed in several human carcinomas. This study investigated aurora $A$ gene copy numbers, mRNA and protein expression as well as tumour cell proliferation and aneuploidy in chromosomal and microsatellite instable sporadic colorectal cancers. Case-matched tissues of normal $(n=71)$ and dysplastic $(n=49)$ colorectal epithelium and invasive carcinomas $(n=71)$ were included in this study. PCR-based microsatellite analysis classified 14/71 $(20 \%)$ of carcinomas as microsatellite instable. A stepwise increase of aurora $A$ mRNA expression $(P<0.0001$; quantitative $\mathrm{RT}-\mathrm{PCR})$ and aurora $A$ protein expressing tumour cells $(P=0.0141$; immunohistochemistry) occurred in the adenoma-carcinoma sequence. Within invasive carcinomas, aurora $A$ mRNA levels $(P=0.0259)$ and aurora A positive tumour cells $(P<0.0001)$ were closely associated with tumour cell proliferation (Ki-67 specific immunohistochemistry). Compared with chromosomal instable carcinomas, microsatellite instable carcinomas had significantly more aurora $A$ positive tumour cells $(P=0.0043)$ and a higher tumour cell proliferation $(P=0.0335)$. In contrast, only chromosomal instable carcinomas exhibited marked tumour cell aneuploidy $(P=0.0004$, fluorescence in situ hybridization) and significantly higher aurora $A$ gene copy numbers $(P=0.0206)$ as compared with microsatellite instable carcinomas. This study further supports a role of aurora $A$ in the carcinogenesis of sporadic colorectal cancers. Moreover, it demonstrates that in a minority of predominantly microsatellite instable carcinomas the presence of aurora A positive tumour cells is merely reflecting tumour cell proliferation. In contrast, the large majority of chromosomal instable carcinomas shows additional (de)regulation of aurora $A$ by gene amplification and concomitant tumour cell aneuploidy. Thus, sporadic colorectal cancers exhibit different mechanisms of aurora A regulation and this may impact the efficacy of aurora-targeted therapies.
\end{abstract}

Modern Pathology (2009) 22, 1385-1397; doi:10.1038/modpathol.2009.111; published online 31 July 2009

Keywords: aurora kinases; sporadic colorectal cancer; aneuploidy; proliferation

The development and progression of colorectal cancer is closely linked to increased genetic instability in the malignant cells. ${ }^{1-3}$ In the large majority of sporadic colorectal cancers, genetic

Correspondence: PD Dr S Lassmann, Institute of Pathology, University Medical Center, Albert-Ludwigs University, Breisacherstr. 115a, Freiburg 79106, Germany.

E-mail: silke.lassmann@uniklinik-freiburg.de

Received 6 February 2009; revised and accepted 26 May 2009; published online 31 July 2009 instability manifests itself by multiple numerical chromosomal alterations (gene amplifications, deletions) and is referred to as chromosomal instability. ${ }^{4-6}$ In a smaller group of sporadic colorectal cancers, defects of the DNA missmatch repair system lead to microsatellite instability. ${ }^{7,8}$ Chromosomal, but less frequently microsatellite instable colorectal cancers exhibit frequent tumour cell aneuploidy. ${ }^{4,9,10}$

Whereas the cause for microsatellite instability has clearly been defined to reside in mutations of 
the mismatch repair genes, the underlying mechanism(s) of chromosomal instability still remain to be fully elucidated. Besides chromosome non-disjunction and/or telomere-related alterations, ${ }^{11,12}$ gross defects in chromosome segregation during cell division may contribute to the development of chromosomal instability and aneuploidy. ${ }^{13}$ Indeed, changes in proteins involved in chromosome segregation-so-called chromosomal passenger proteins ${ }^{14-18}$ —and/or proteins involved in mitotic spindle ${ }^{19-21}$ have been associated with the development of aneuploidy in cancer cells. Also, the adenomatosis polyposis coli protein, whose alteration is observed in early colorectal carcinogenesis, ${ }^{22,23}$ has recently been implicated in the control of chromosome segregation during mitosis. $^{24-27}$ Deregulation of chromosome segregation, either directly or indirectly linked to expression and/or modification of adenomatosis polyposis coli, ${ }^{24,25,28}$ may contribute to the characteristic broad genomic alteration of tumour cell aneuploidy or polyploidy. Moreover, it is by now well established that deregulation of centrosomes may be a key event that contributes to or primarily induces aneuploidy. ${ }^{29,30}$ In particular, supernumerary centrosomes, caused by overexpression of (the numerous) proteins of the centrosome complex, may promote a failure in appropriate chromosome segregation and result in tetra-, poly and/or aneuploid daughter cells.

The protein family of aurora kinases (-A, -B, -C) is involved in the centrosomal complex (aurora $\mathrm{A}$ ) and in the chromosomal passenger complex (aurora $\mathrm{B})^{31-34}$ and has gained substantial attention in view of its potential therapeutic value in diverse solid tumour entities. ${ }^{35-38}$ In particular, overexpression of aurora A induces supernumerary centrosomes and aneuploidy. ${ }^{31-34,39}$

In tissue specimens of colorectal cancer, aurora $\mathrm{A}$ is amplified and overexpressed as determined by Southern and northern blotting of tissue extracts, ${ }^{40}$ by quantitative PCR $^{41}$ as well as immunohistochemistry. ${ }^{42-44}$ We recently showed by quantitative RTPCR that step-wise aurora A mRNA upregulation occurs during colorectal carcinogenesis, especially in chromosomal instable carcinomas. ${ }^{45}$ In addition, our array-based comparative genomic hybridisation analysis suggested that chromosomal instable carcinomas exhibit preferential amplification of the aurora $A$ gene locus at 20q13. ${ }^{46}$ Similarly, Nishida et $a l^{41}$ found that microsatellite instable colorectal cancers rarely have aurora $A$ gene amplification, as measured by PCR. By mRNA expression profiling of microdissected invasive cancer cells from formalinfixed and paraffin-embedded colorectal cancers, we recently also detected aurora A as one prominently expressed gene in chromosomal instable tumours. ${ }^{47}$ Finally, in vitro, ectopic aurora A overexpression in tumour cells induces aneuploidy ${ }^{39}$ and may convert microsatellite instable into aneuploid (chromosomal instable like) colorectal tumour cells. ${ }^{48}$
These data clearly point towards differential regulation and expression of aurora $\mathrm{A}$ in subtypes of colorectal cancers. Still, the clinically relevant aspect of aurora A 'over'expression has so far been mostly defined by the presence of an elevated number of aurora A positive tumour cells. As aurora A expression also changes tightly within the cell cycle ${ }^{49,50}$ the previously observed aurora $A$ gene amplification $^{40,41}$ and particularly the aurora A overexpression in colorectal cancers ${ }^{40,42-44}$ may have been influenced by the fraction of proliferating tumour cells.

The aim of this study was therefore to analyse aurora A expression and regulation in the adenomacarcinoma sequence of sporadic colorectal cancers. Specifically, we tested whether sporadic chromosomal and microsatellite instable carcinomas display differences in aurora A regulation and expression by gene amplification and/or proliferation and whether this is linked to differences of chromosomal and microsatellite instability associated (aneu-)ploidy.

\section{Materials and methods}

\section{Patients}

The study included formalin-fixed and paraffinembedded specimens of 71 patients resected for sporadic colorectal cancer (median age of patient$\mathrm{s}=72$ years; Table 1). Samples of normal colonic mucosa ( $n=71$, obtained from resection margins), low $(n=36)$ - and high $(n=13)$-grade intraepithelial neoplasia and invasive colorectal carcinomas $(n=71)$ were included.

Normal epithelium, dysplastic epithelium (adenoma) and invasive carcinoma tissue samples were obtained from primary resection specimens of the same cases. Normal epithelium was obtained from resection margins at least $15 \mathrm{~cm}$ away from the invasive carcinomas. Adenomas-if present in the resection specimen-were derived from separate locations at distance from the invasive carcinomas, thereby ruling out a bias due to carcinoma-associated dysplastic lesions.

Data of low- and high-grade intraepithelial neoplasia samples were combined as 'dysplastic epithelium' for statistical purposes. The histopathological characteristics of all patients are displayed in Table 1, with specific reference to the subgroups of cases with chromosomal and microsatellite instable carcinomas. For classification of microsatellite instable carcinomas, microsatellite analysis was performed by analysis of five microsatellite loci in DNA derived from microdissected tumour cells and normal epithelial cells as before. ${ }^{45}$ Three of 71 cases yielded uninformative data and were excluded from statistical analyses addressing differences between chromosomal and microsatellite instability. Appropriate tissues samples were selected after re-classification $^{51,52}$ of hematoxylin and eosin-stained sections by an experienced pathologist (MD), as 
Table 1 Clinicopathological parameters of sporadic colorectal cancer patients investigated

\begin{tabular}{|c|c|c|c|}
\hline & All cases & $\begin{array}{l}\text { Chromosomal } \\
\text { instable cases* }\end{array}$ & $\begin{array}{l}\text { Microsatellite } \\
\text { instable cases* }\end{array}$ \\
\hline $\begin{array}{l}\text { Number of cases } \\
(N)\end{array}$ & 71 & 54 & 14 \\
\hline \multicolumn{4}{|l|}{ Sex } \\
\hline Male & 44 & 35 & 6 \\
\hline Female & 27 & 19 & 8 \\
\hline Age & 72 & 72 & 76 \\
\hline (median, range) & $(46-90)$ & $(46-88)$ & $(67-90)$ \\
\hline \multicolumn{4}{|l|}{ Location } \\
\hline Colon & 63 & 46 & 14 \\
\hline Rectum** & 8 & 8 & 0 \\
\hline \multicolumn{4}{|l|}{ Tissue samples $(\mathrm{N})$} \\
\hline $\begin{array}{l}\text { Normal } \\
\text { epithelium }\end{array}$ & 71 & 54 & 14 \\
\hline $\begin{array}{l}\text { Dysplastic } \\
\text { epithelium }\end{array}$ & 49 & 40 & 6 \\
\hline$(L G I N, H G I N)$ & $(36,13)$ & $(30,10)$ & $(4,2)$ \\
\hline $\begin{array}{l}\text { Invasive } \\
\text { carcinoma }\end{array}$ & 71 & 54 & 14 \\
\hline \multicolumn{4}{|l|}{$\begin{array}{l}\text { Tumour } \\
\text { classification }\end{array}$} \\
\hline pT1 & 3 & 3 & 0 \\
\hline pT2 & 9 & 7 & 2 \\
\hline pT3 & 53 & 38 & $1 \overline{2}$ \\
\hline pT4 & 6 & 6 & 0 \\
\hline pNo & 46 & 34 & 10 \\
\hline pN1 & 11 & 10 & 1 \\
\hline $\mathrm{pN} 2$ & 11 & 8 & 2 \\
\hline $\mathrm{pNx}$ & 3 & 2 & 1 \\
\hline \multicolumn{4}{|l|}{ Tumour grading } \\
\hline G1 & 5 & 5 & 0 \\
\hline G2 & 48 & 37 & 8 \\
\hline G3 & 18 & 12 & 6 \\
\hline
\end{tabular}

The table summarizes the major clinicopathological parameters of the investigated cases and the tissue materials used for all cases as well as for chromosomal and microsatellite instable cases separately.

Note: *For three cases, no MSI-status could be obtained; **no neoadjuvant radio/chemotherapy.

LGIN and HGIN = low- and high-grade intraepithelial neoplasia.

described before for 41 of the cases. ${ }^{45,46}$ The study had been approved by the local Ethics Committees (\#251/04 Ethik-Kommission, Albert-Ludwigs-Universität, Freiburg, Germany; and the University Medicine and Pharmacy, Department of Pathology, Iasi, Romania).

\section{Analysis of Aurora A mRNA Expression}

We had previously determined aurora A mRNA levels in 41 cases $^{45}$ and in this study examined aurora A mRNA levels of the additional 30 new cases. For this, and as before, ${ }^{45}$ RNA extracts of microdissected cell populations (normal or dysplastic epithelial cells, invasive tumour cells) of formalin-fixed and paraffin-embedded tissue speci- mens were prepared and subjected to quantitative RT-PCR (qRT-PCR) analysis using established proto$\operatorname{cols}^{45,47,53}$ and the comparative Ct-method ${ }^{54}$ for final calculation of aurora A mRNA expression levels. Of all tissue samples analysed, 183/191 (96\%) yielded sufficient RNA of appropriate quality for qRT-PCR analysis (acceptable signals for both reference gene/ TATA box binding protein, target gene/aurora $A$ ). Failures to obtain sufficient mRNA and/or appropriate signals in qRT-PCR analysis (reference gene/ TATA box binding protein, target gene/aurora $A$ ) were observed in $1 / 71$ (1\%) normal epithelium samples, 3/49 (6\%) dyspastic samples and 5/71 $(7 \%)$ invasive carcinoma samples.

\section{Analysis of Aurora A Protein Expression and Tumour Cell Proliferation}

For analysis of aurora A protein expression and tumour cell proliferation, tissue microarrays were constructed from representative tissue areas (normal and dysplastic epithelium, invasive carcinoma) by punching $0.2 \mathrm{~cm}$ cores per tissue sample. Comparative analyses of entire tissue sections and $0.2 \mathrm{~cm}$ cores demonstrated that staining patterns were homogeneous throughout the selected tissue blocks. Serial tissue microarray sections of $4 \mu \mathrm{m}$ thickness were subjected to immunohistochemistry with aurora $\mathrm{A}^{53}$ and $\mathrm{Ki} 67^{55,56}$-specific antibodies. In brief, sections were cut, dried and deparaffinized. Antigen retrieval was done by boiling sections in Tris-EDTA buffer pH9 (aurora A) or citrate buffer pH6 (Ki67), followed by incubation with primary antibodies for aurora A (1:50, aurora kinase 2, clone JLM28, Loxo/ Novocastra, Dossenheim, Germany) and Ki67 (clone MIB-1, 1:500; DakoCytomation) for $60 \mathrm{~min}$. Secondary antibodies were incubated for $30 \mathrm{~min}$ and detection was with the LSAB-Fast red System (DakoCytomation). Positive controls for aurora $\mathrm{A}^{44}$ and Ki67 protein stainings were routinely processed formalin-fixed and paraffin-embedded tonsils and negative controls sections were stained by omission of the primary antibody. All stainings were performed on a DAKOAutostainer (DakoCytomation) and evaluated semi-quantitatively in tumour cells with scores for cytoplasmic and nuclear aurora A staining as before ${ }^{53}$ (Figure 1) and scores for nuclear Ki67 staining: score $0=$ all tumour cells negative, score $1=<10 \%$ tumour cells positive, score $2=10-$ $50 \%$ tumour cells positive and score $4=>50 \%$ positive. ${ }^{56}$

\section{Analysis of Aurora A Gene Copy Numbers and Aneuploidy by Fluorescence In Situ Hybridisation}

Aurora $A$ gene copy numbers ${ }^{46,53}$ and tumour cell aneuploidy were assessed as follows: Serial tissue microarray sections of $5 \mu \mathrm{m}$ thickness were subjected to deparaffination, pre-treatment in pH6 citrate buffer in a microwave oven $(180 \mathrm{~W})$ for 

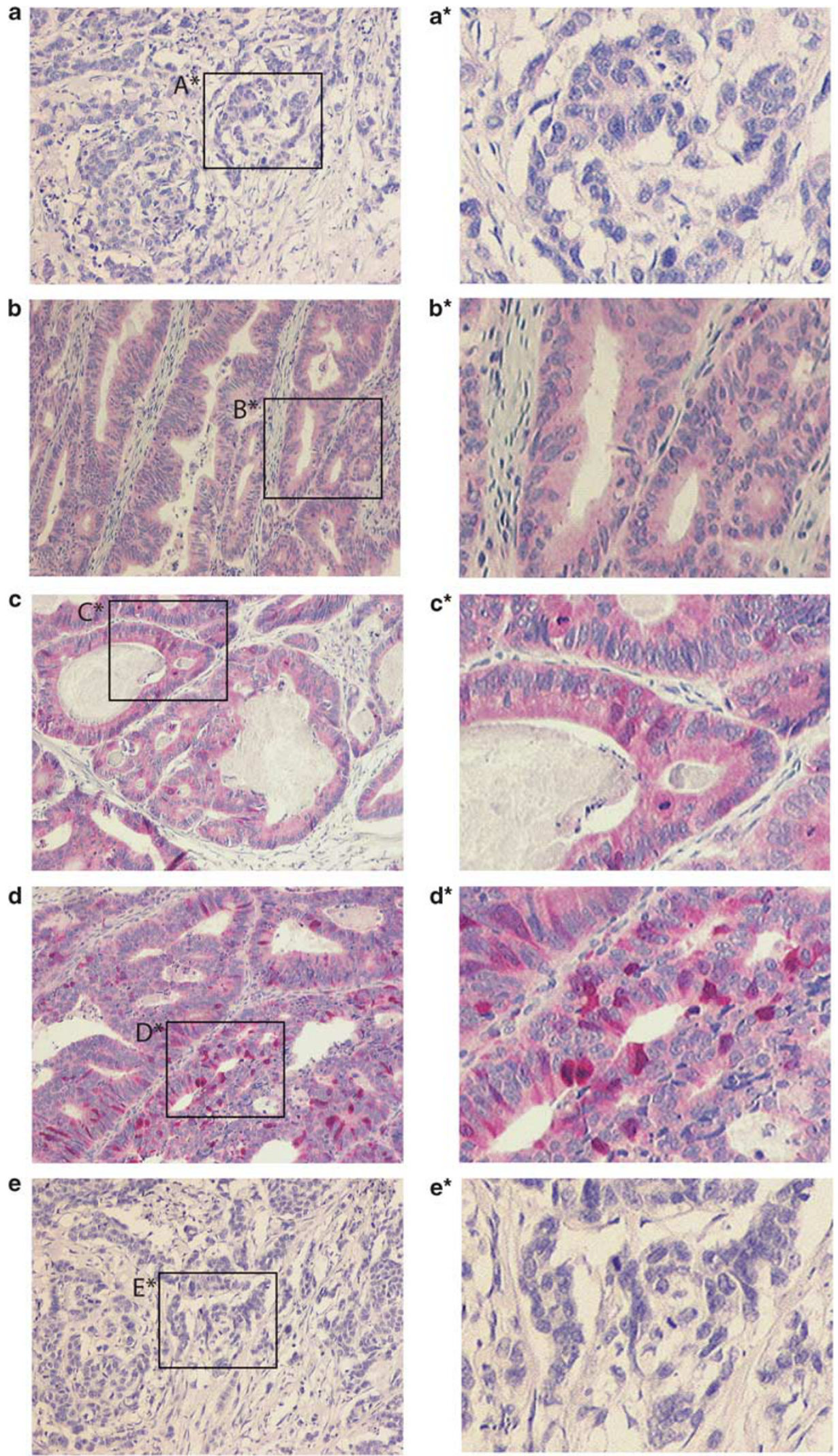

Figure 1 Representative immunohistochemical stainings of aurora A protein expression in sporadic colorectal cancers. The figure shows representative photographs of sections stained with an aurora A specific antibody. (a-d) (magnification $\times 100$ ): Four examples of invasive carcinomas with immunohistochemistry score 0 (a; case \#23; chromosomal instable), 1 (b; case\# 13; microsatellite instable), 2 (c; case \#16; chromosomal instable) and 3 (d; case \# 5; chromosomal instable). (e) Negative control staining (no primary antibody; case\# 23). $A^{*}-E^{*}($ magnification $\times 200)$ : enlarged inserts from a-e. 
$20 \mathrm{~min}$ and Pronase E (0.05\%) digestion for $3 \mathrm{~min}$ at $37^{\circ} \mathrm{C}$. Subsequently, sections were denatured in $2 \times \mathrm{SSC} / 50 \%$ Formamide (room temperature), and $2 \times \mathrm{SSC} / 70 \%$ Formamide $\left(75^{\circ} \mathrm{C}, 15 \mathrm{~min}\right)$, immersed in ice cold ethanols (70, 95 and 100\%, 5 min each) and dried at $37^{\circ} \mathrm{C}$. In the meantime, the fluorescence in situ hybridization (FISH) probes had been denatured $\left(75^{\circ} \mathrm{C}, 5 \mathrm{~min}\right)$ and were hybridised to the dried sections $\left(16 \mathrm{~h}, 37^{\circ} \mathrm{C}\right)$ as follows: Section (i) probe specific for the aurora $A$ gene and centromere 20 (chromosome enumeration probe, CEP20; Chrombios, Raubling, Germany) $)^{46,53}$ and section (ii) to (v) probes specific for CEP7, CEP8, CEP11 (Abbott Vysis) and CEP13 (QBiogen). After hybridization, sections were washed in $2 \times$ SSC (room temperature) and in $2 \times \mathrm{SSC}\left(73^{\circ} \mathrm{C}\right.$, for $\left.2 \mathrm{~min}\right)$, cover-glassed with DAPI-containing mounting medium (Vector) and stored at $-20^{\circ} \mathrm{C}$ until analysis. Stained sections were evaluated on a fluorescence microscope (Axioplan 2 imaging with ApoTome system, Carl Zeiss MicroImaging GmbH, Göttingen, Germany) by taking image stacks at $0.5-1.0 \mu \mathrm{m}$ intervals for each three representative areas per case $(63 \times$ magnification). Image stacks were converted into $3 \mathrm{D}$ view by AxioVision software and then assessed for Aurora $A$ - (section i) and centromere- (sections $\mathrm{i}-\mathrm{v}$ ) specific signals.

For aurora $A$ gene copy numbers, FISH data are presented as the mean number of aurora $A$ gene- and CEP-specific signals per tumour cell per case. A mean of $67 \pm 21$ tumour cells (range, 13-100) were counted per case. The ratio of the mean aurora $A$ gene- to CEP20-specific signals per cell was calculated to assess aurora $A$ gene amplification for each case.

For determination of tumour cell aneuploidy by FISH, ${ }^{57}$ first 20 samples of normal colonic epithelium were analysed with FISH probes specific for CEP7, CEP8, CEP11, CEP13, CEP20. The mean CEPspecific signals per normal epithelial cell were (number of cells counted in brackets): CEP7: $2.13 \pm 0.2 \quad(n=131) ; \quad$ CEP8: $2.17 \pm 0.12 \quad(n=140)$; CEP11: $2.23 \pm 0.07 \quad(n=140) ; \quad$ CEP13: $2.1 \pm 0.18$ $(n=130)$ and CEP20: $2.01 \pm 0.11(n=98)$. The mean $(2.15) \pm 3$ standard deviations $(3 \times 0.15)$ of all five CEP-signals per normal epithelial cell was 2.6 and this was set as cut-off for classification of aneuploidy in invasive tumour cells. In invasive carcinomas, a mean of $88 \pm 25$ tumour cells per case (range, 2-105) were evaluated for the five CEP-signals and the corresponding mean calculated.

\section{Statistics}

Statistical evaluation included experimental data of aurora A mRNA (qRT-PCR: dCT values) and protein (immunohistochemistry: scores 0-3) expression, aurora $A$ gene- and CEP20-specific FISH signals, tumour cell proliferation (Ki67-specific immunohistochemistry: scores 0-2), ploidy (diploid or aneuploid) and microsatellite status as well as clinicopathological parameters of tumour $\mathrm{T}$ and $\mathrm{N}$ category and tumour grading. Samples of low- and highgrade intraepithelial neoplasia were combined as 'dyspastic epithelium' for these analyses and three cases were excluded from comparisons of chromosomal and microsatellite instable cases, due to lacking microsatellite status. Correlations between parameters were performed using the Spearman correlation coefficient. Wilcoxon signed rank test was applied to compare continuous parameters of paired samples. Frequency tables were tested by Fisher's exact test for comparison of binary parameters. A $P$-value of $<0.05$ was considered significant.

\section{Results}

Aurora A Expression in the Adenoma-Carcinoma Sequence of Sporadic Colorectal Cancer

Aurora A mRNA and protein expression was determined in case-matched normal and dysplastic epithelium and invasive carcinomas of 71 cases with sporadic colorectal cancer. ${ }^{45,46}$

As shown in Figure 2a and Table 2, significant upregulation of aurora A mRNA expression occurred between normal and dysplastic epithelium $(P=0.0008)$ as well as between dysplastic epithelium and invasive carcinoma $(P=0.0001)$. Aurora A mRNA expression was significantly higher in invasive carcinomas than normal epithelium $(P<0.0001)$. Similarly, the frequency of aurora $A$ protein expressing (hereafter referred to as 'aurora A positive') cells increased significantly from dysplastic epithelium to invasive carcinoma $(P=0.0027)$ and was markedly higher in invasive carcinomas as compared with normal epithelium $(P=0.001)$ (Figures 1 and $2 \mathrm{~b}$; Table 2). There were, however, no significant differences in the number of aurora $\mathrm{A}$ positive cells in normal and dysplastic epithelium $(P=1.000)$.

In invasive carcinomas, aurora A mRNA expression and aurora A positive tumour cells were significantly correlated between each other $(P=0.0151)$. High numbers of aurora A positive tumour cells were preferentially found in nodenegative cases (pNo category; $P=0.0419$ ) but were not associated with pT category $(P=0.9316)$ or tumour grading $(P=0.5864)$.

\section{Analysis of Aurora $A$ Gene Copy Numbers and Tumour Cell (Aneu)ploidy}

To examine aurora $A$ gene copy numbers and tumour cell ploidy, ${ }^{4,9,10,34,35,39,40}$ serial sections of 39/71 invasive carcinomas in which aurora A expression had been measured, were subjected to established FISH-based analyses. ${ }^{46,53,57}$ 

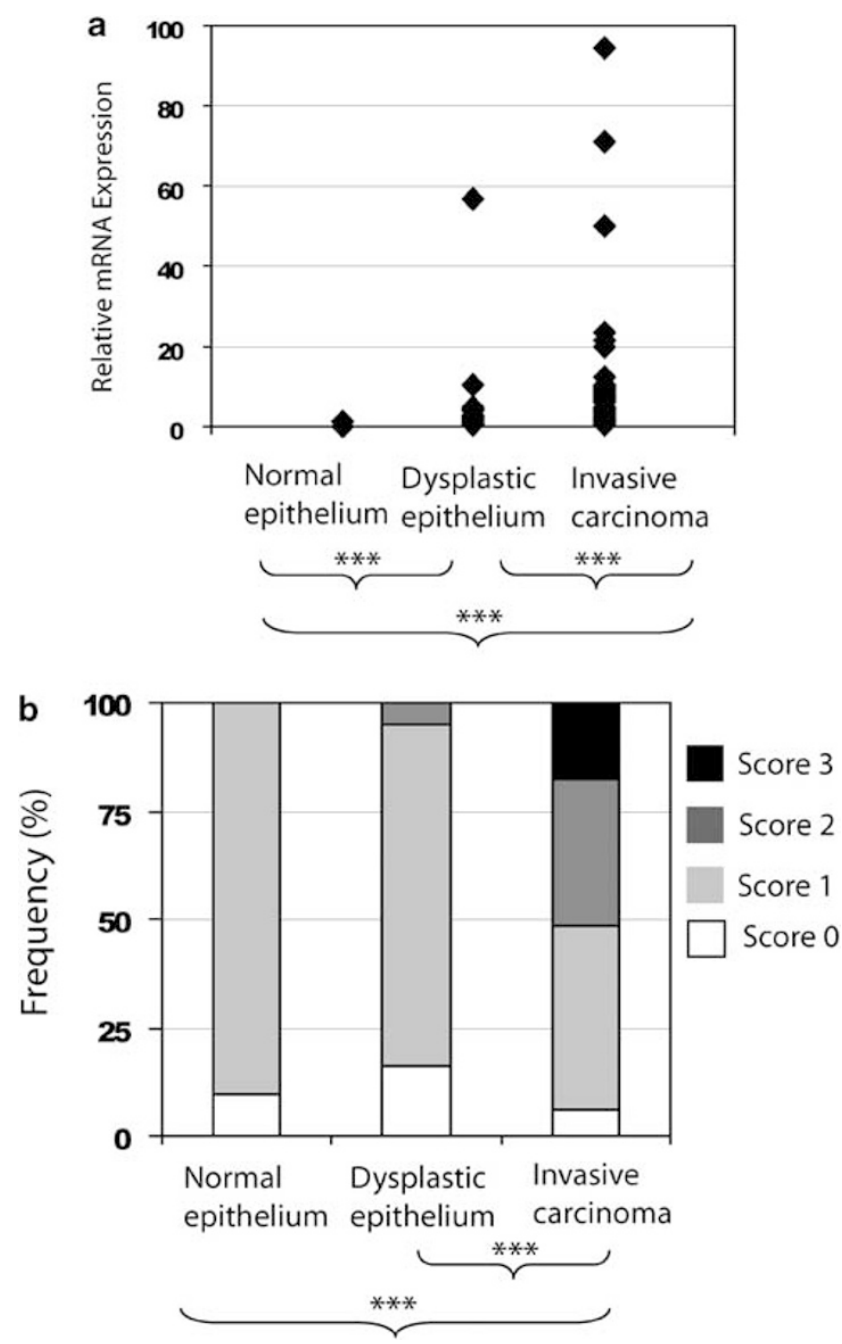

Figure 2 Aurora A mRNA and protein expression in the carcinogenesis of sporadic colorectal cancers. The graphs summarize findings of relative aurora A mRNA levels determined by qRT-PCR (a) and aurora A protein expression determined by semiquantitative immunohistochemistry (b). Note the significant increase of aurora A mRNA expression from normal to dysplastic to invasive epithelial cells (a). The increase of aurora A mRNA expression is paralleled by a significant increase of the frequency of aurora A positive cells from dysplastic epithelia to invasive carcinoma (b). Significant correlations are marked by brackets with $* * *(P$-values are given in the main text).

As exemplarily shown in Figure 3a-d, FISH revealed a wide range of aurora $A$ gene- (2.18-14.40) and CEP20- (2.00-14.62) specific signals, generally elevated above the normal copies of 2 (Table 3; Figure 3a-d). Low level of aurora $A$ gene amplification (defined as aurora A/CEP20 signal ratio > 1.25) was detected in 15/39 (38.5\%) invasive carcinomas.

Having defined a cut-off for aneuploidy by analysis of the five CEP probes in normal epithelial cells (cut-off $=2.6$, Materials and methods), 20/39 $(51.3 \%)$ of invasive carcinomas showed marked aneuploidy (Figure 3e; Table 3). Elevated aurora $A$ gene- $(P=0.0001)$ and CEP20- $(P=0.0002)$ specific FISH signals were significantly linked to tumour cell aneuploidy (Figure 3e).

\section{Comparison of Chromosomal- and Microsatellite Instable Sporadic Colorectal Carcinomas}

Alterations of chromosome 20q13 and/or the aurora $A$ gene appear to occur preferentially in (aneuploid $^{4,9,10}$ ) chromosomal instable colorectal cancers. ${ }^{39-42,46,48}$ We therefore compared ploidy and aurora A specific DNA, mRNA and protein levels in chromosomal $(n=30)$ versus microsatellite $(n=10)$ instable sporadic colorectal carcinomas.

Aneuploidy was exclusively seen in invasive carcinomas with chromosomal (20/30;67\%), but not microsatellite $(0 / 10 ; 0 \%)$ instability $(P=0.0004$; Figure 3e; Table 3). In addition, chromosomal instable invasive carcinomas exhibited significantly higher aurora A specific FISH signals (range, 2.1814.40) as compared with microsatellite instable invasive carcinomas (range, 2.70-4.30) $(P=0.0206$; Figure 3e; Table 3). CEP20-specific FISH signals also tended to be elevated in chromosomal instable invasive carcinomas (Figure 3e; Table 3), but this did not reach significance $(P=0.0853)$.

Whereas we did not detect a significant difference between sporadic chromosomal and microsatellite instable invasive carcinomas at the aurora A mRNA level $(P=0.8427)$, surprisingly microsatellite instable invasive carcinomas displayed significantly higher numbers of aurora A positive tumour cells $(P=0.0043$; Figure 4a).

\section{Correlation of Aurora A Expression to Tumour Cell Proliferation}

Since aurora A function is tightly associated with the cell cycle, ${ }^{49,50}$ we next examined whether the high number of aurora A positive tumour cells in microsatellite instable invasive carcinomas is simply reflecting a high rate of tumour cell proliferation.

Indeed, by semi-quantitative evaluation of tumour cell proliferation using Ki67-specific immunohistochemistry, ${ }^{55,56}$ microsatellite instable invasive carcinomas exhibited significantly higher tumour cell proliferation as chromosomal instable invasive carcinomas $(P=0.0335$, Figure $4 \mathrm{~b})$, an observation previously reported by others. ${ }^{58}$ Moreover, aurora A mRNA $(P=0.0259)$ and protein $(P<0.0001)$ expression was closely linked to tumour cell proliferation.

\section{Discussion}

In sporadic colorectal cancers, chromosomal instability occurs in up to $80 \%$ of cases and manifests with broad genomic and gene-specific copy number changes as well as with overall tumour cell aneuploidy. ${ }^{1-6,9,10}$ The detailed mechanism(s) of chromosomal instability still remain to be fully elucidated, but gross defects in chromosome segregation appear to be involved. ${ }^{13}$ As such, changes in proteins of the so-called chromosomal 
Table 2 Summary of aurora A mRNA and protein expression in the carcinogenesis of sporadic colorectal cancers

\begin{tabular}{|c|c|c|c|c|}
\hline & \multirow[t]{2}{*}{ Normal epithelium } & \multicolumn{2}{|c|}{ Dysplastic epithelium } & \multirow[t]{2}{*}{ Invasive carcinome } \\
\hline & & $(L G I N)$ & (HGIN) & \\
\hline \multicolumn{5}{|c|}{ Aurora A mRNA } \\
\hline n/N (\%) & $70 / 71(99 \%)$ & $34 / 36(94 \%)$ & $12 / 13(92 \%)$ & $66 / 71(93 \%)$ \\
\hline Mean \pm s.d. & 1 & $1.59( \pm 1.1)$ & $7.41( \pm 15.8)$ & $8.08( \pm 15.2)$ \\
\hline \multicolumn{5}{|c|}{ Aurora A protein } \\
\hline Score 0 & $6 / 64(9 \%)$ & 6/31 (19.4\%) & 1/12 (8\%) & 4/68 (6\%) \\
\hline Score 1 & $58 / 64(91 \%)$ & $25 / 31(80.6 \%)$ & $9 / 12(75 \%)$ & $29 / 68(43 \%)$ \\
\hline Score 2 & - & - & $2 / 12(17 \%)$ & $23 / 68(34 \%)$ \\
\hline Score 3 & - & - & - & $12 / 68(17 \%)$ \\
\hline
\end{tabular}

The table summarizes the findings of qRT-PCR and immunohistochemical analyses for aurora A mRNA and protein expression in normal and dysplastic epithelium and invasive carcinomas. Aurora A mRNA: The number of cases $(n / N$, percentage) with acceptable qRT-PCR results and mean relative aurora A mRNA levels (mean \pm s.d.) are given for low- (LGIN) and high (HGIN)-grade intraepithelial neoplasia and invasive carcinomas as compared with normal epithelium (set to ' 1 '). Aurora A protein expression is presented as the frequency, given as number/ $N$ (percentage), of samples for each immunohistochemistry score. Note that there were no marked differences between samples of low- and highgrade intraepithelial neoplasia (mRNA: $P$-value $=0.530$; protein: $P$-value $=0.085$ ), which were therefore combined as 'dysplastic epithelium' for further analyses (Figure 2, main text).

passenger complex and/or proteins involved in mitotic spindle function have been associated with the development of aneuploidy in cancer cells. ${ }^{13-21}$ Moreover, proteins of the centrosomal complex have received substantial experimental attention as key regulators of cellular ploidy..$^{29,30}$ Alteration of the centrosomal kinase aurora $\mathrm{A}^{31-34}$ by gene amplification and/or overexpression has been associated with induction of supernumerary centrosomes and/or aneuploidy in several gastrointestinal, eg esopha-

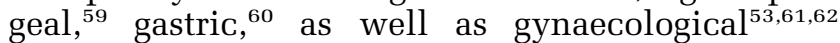
carcinomas.

In particular, aurora A overexpression has also been observed in colorectal cancer cell lines and/or tissues, in which it is linked to aneuploidy. ${ }^{39-48}$ However, a precise investigation of aurora A expression at the RNA and protein level within the adenoma-carcinoma sequence, and/or within the different subtypes of chromosomal and microsatellite instable sporadic colorectal cancers has so far not been preformed. Moreover, it is still unclear whether aurora A overexpression in colorectal cancers is merely a reflection of tumour cell proliferation ${ }^{49,50}$ and, in this context, has no effects on chromosomal instability and/or aneuploidy. This central question still needs to be answered in view of the ongoing discussion of therapeutically targeting aurora kinases in solid tumours. ${ }^{35-38}$ It is conceivable that differential aurora A regulation and expression may effect the efficacy of aurora inhibitors: for example, colorectal cancers with high numbers of tumour cells only seemingly 'over'expressing aurora A due to active proliferation, may respond differently to aurora inhibitors as compared with colorectal cancers with few aurora A positive tumour cells, but in which aurora A expression is associated with gene amplification, aberrant centrosome function and/or chromosomal instability. In this study, we therefore addressed these aspects in 71 cases of sporadic colorectal cancers, focussing on chromosomal and microsatellite instable invasive carcinomas.

Our current data supports previous findings ${ }^{39-48}$ that, in general, aurora A overexpression occurs at the mRNA and protein level in invasive colorectal cancers. In the adenoma-carcinoma sequence, the first increase of aurora A mRNA expression occurs at the transition of normal to dysplastic epithelium, but significant aurora A protein overexpression does only take place at the transition from dysplastic epithelium to invasive carcinoma. Statistical comparison of aurora A mRNA or protein expression between the samples of low- and high-grade intraepithelial neoplasia revealed no significant differences and these tissue samples had therefore been combined as 'dysplastic epithelium'. The observed lack of a close association of aurora A mRNA and proteins levels in dysplastic epithelium may be due to potential post-transcriptional modifications and, in particular, aurora $\mathrm{A}$ protein dynamics. ${ }^{63,64}$ Together, these results may in part reflect a general increase of proliferating dysplastic and/or invasive tumour cells. However, as low level of aurora $A$ gene amplification (aurora $A$ /CEP20 ratio $>1.25$ ) was clearly present in $40 \%$ of invasive carcinomas, additional levels of aurora $A$ regulation appear to be involved in sporadic colorectal cancers.

Indeed, comparative analyses between chromosomal and microsatellite instable invasive carcinomas strengthened the hypothesis that (de)regulation of aurora A expression occurs-uncoupled from proliferation-also at the level of aurora $A$ gene copy numbers. Our detailed FISH analysis of serial tissue specimens of invasive carcinomas revealed that this occurs exclusively in those with chromosomal instability ${ }^{45,46}$ and correlates with aneuploidy. ${ }^{39,41,46,48}$ Surprisingly, our analyses revealed that, despite aneuploidy and increased aurora $A$ gene copy numbers in chromosomal 


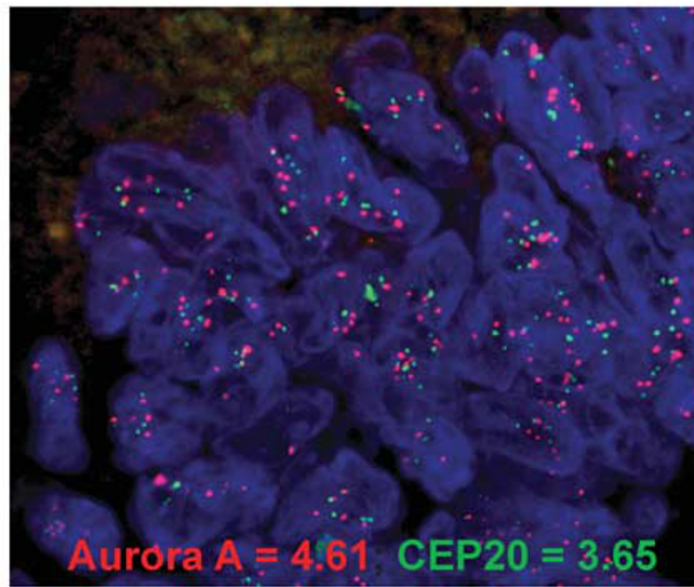

c

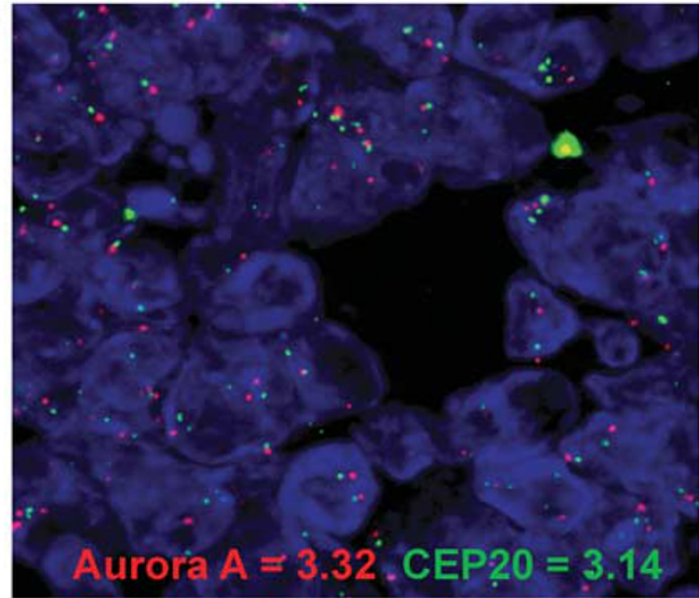

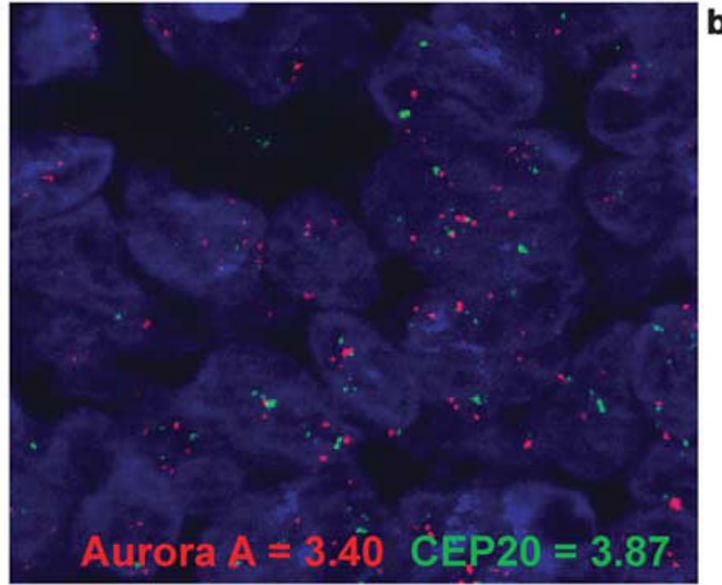

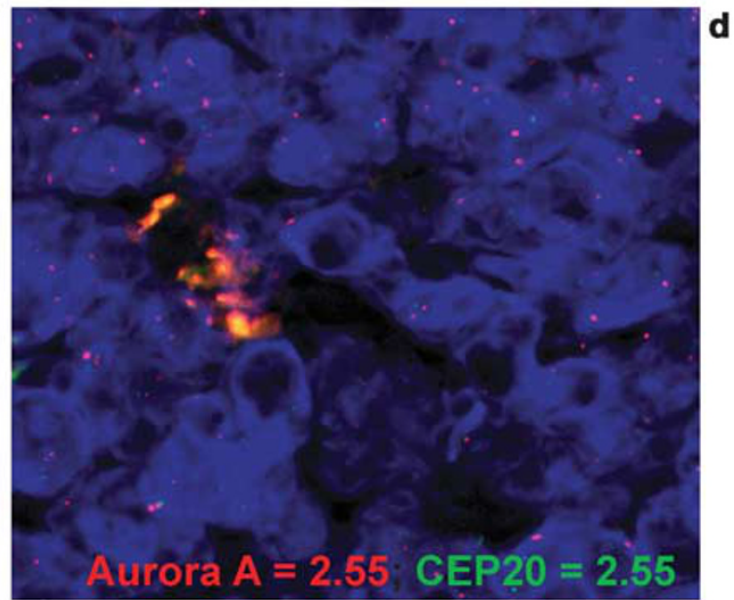

e

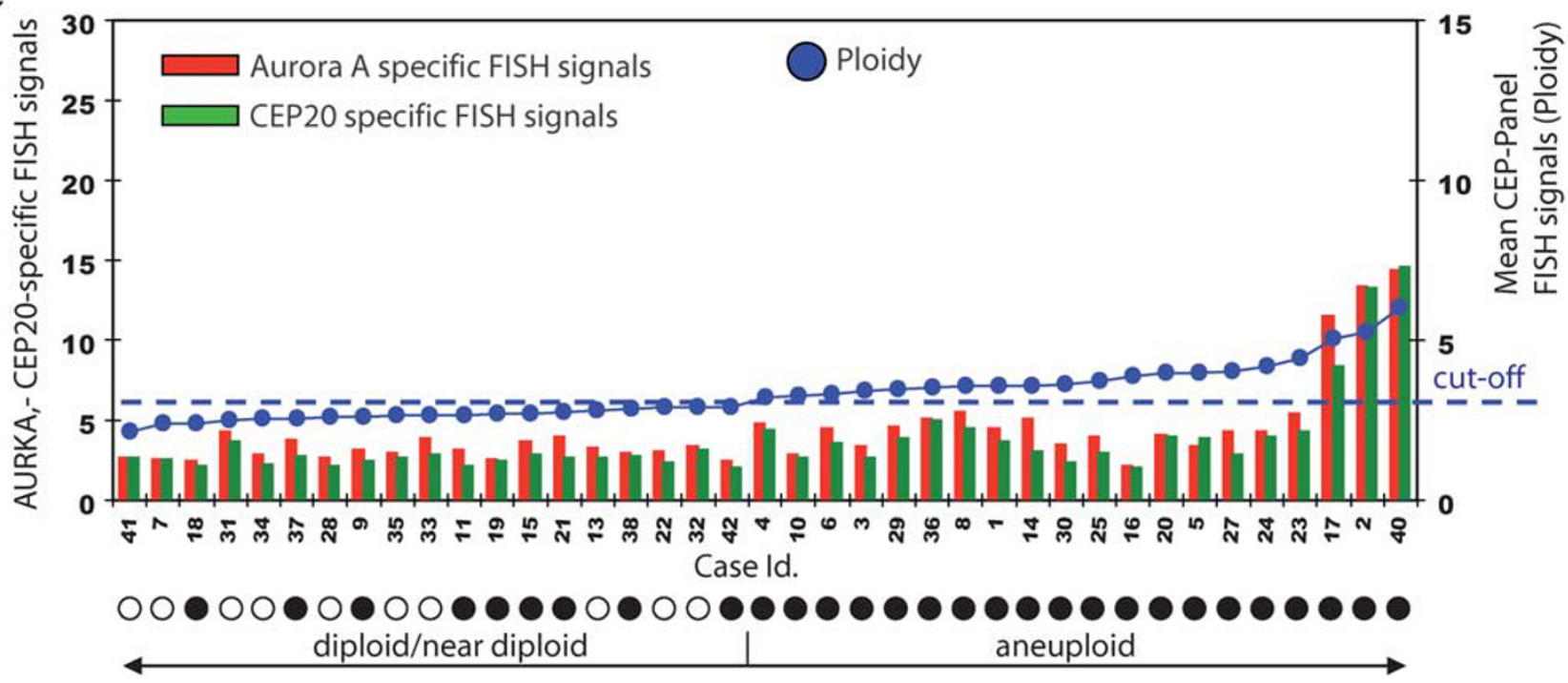

Figure 3 Aurora A gene- and centromere 20-specific fluorescence in situ hybridization analysis and summary of ploidy in sporadic colorectal cancers. (a-d) Show four representative 3D-image stacks of aurora A-(red signals) and CEP20- (green signals) specific fluorescence in situ hybridization (FISH) analysis (cell nuclei counterstained with DAPI/blue), with chromosomal instable invasive carcinomas in a (case \#29) and $\mathbf{b}$ (case \#5) and microsatellite instable invasive carcinomas in $\mathbf{c}$ (case \#32) and $\mathbf{d}$ (case \#7). Aurora A geneand CEP-specific FISH signals (mean of $67 \pm 21$ tumour cells per case) are given below each panel. (e) Summarizes the aurora $A$ gene(red bars) and CEP20- (green bars) specific FISH signals (left $y$-axis) and the mean count of the multi-centromere FISH panel ('ploidy'; blue closed circles, right $y$-axis). The cut-off for aneuploidy was 2.6 (dashed blue line, right $y$-axis). Note that aneuploid invasive carcinomas were exclusively chromosomal instable (black closed circles below $x$-axis) and that microsatellite instable invasive carcinomas (black open circles below $x$-axis) were diploid/near diploid with generally lower aurora $A$ gene- and CEP20-specific FISH signals as compared with chromosomal instable invasive carcinomas. 
Table 3 Case-specific summary of clinicopathological parameters and experimental data of sporadic chromosomal and Microsatellite instable invasive colorectal carcinomas

\begin{tabular}{|c|c|c|c|c|c|c|c|c|c|c|c|}
\hline \multicolumn{5}{|c|}{ A: Chromosomal instable } & \multicolumn{4}{|c|}{ FISH analysis } & \multirow{2}{*}{$\begin{array}{c}\text { Q-RT-PCR analysis } \\
\text { Aurora } A\end{array}$} & \multicolumn{2}{|c|}{ IHC analysis } \\
\hline Case Id. & $p T$ & $p N$ & $G$ & Histology & Ploidy & Aurora A & CEP2O & Aurora A:CEP2O & & Aurora A & Ki67 \\
\hline 23 & 4 & 2 & 3 & Tub & Aneuploid & 5.36 & 4.27 & 1.26 & 3.41 & 0 & 3 \\
\hline 40 & 3 & 0 & 2 & Tub & Aneuploid & 14.40 & 14.62 & 0.98 & 9.65 & 0 & 0 \\
\hline 42 & 3 & 0 & 2 & Tub & Diploid & 2.50 & 2.00 & 1.25 & 1.00 & 1 & 1 \\
\hline 19 & 3 & 0 & 2 & Tub & Diploid & 2.58 & 2.47 & 1.04 & 2.55 & 1 & 2 \\
\hline 11 & 2 & 0 & 1 & Tub & Diploid & 3.21 & 2.11 & 1.52 & 7.78 & 1 & 0 \\
\hline 30 & 3 & 2 & 3 & Tub & Aneuploid & 3.47 & 2.38 & 1.46 & 1.83 & 1 & 1 \\
\hline 15 & 3 & 2 & 2 & Muc & Diploid & 3.71 & 2.81 & 1.32 & 2.60 & 1 & 3 \\
\hline 37 & 3 & 0 & 2 & Muc & Diploid & 3.79 & 2.77 & 1.37 & 0.23 & 1 & 3 \\
\hline 25 & 2 & 0 & 2 & Tub & Aneuploid & 3.95 & 2.97 & 1.33 & 2.17 & 1 & 3 \\
\hline 27 & 1 & 2 & 2 & Tub & Aneuploid & 4.24 & 2.87 & 1.48 & 8.22 & 1 & 2 \\
\hline 24 & 3 & 1 & 2 & Tub & Aneuploid & 4.28 & 4.00 & 1.07 & 4.96 & 1 & 1 \\
\hline 8 & 3 & 0 & 2 & Tub & Aneuploid & 5.48 & 4.45 & 1.23 & 2.11 & 1 & 3 \\
\hline 39 & 3 & 0 & 2 & Tub & ND & ND & ND & ND & ND & 1 & 0 \\
\hline 16 & 3 & 0 & 2 & Tub & Aneuploid & 2.18 & 2.00 & 1.09 & 0.27 & 2 & 0 \\
\hline 38 & 3 & 1 & 3 & Tub & Diploid & 3.01 & 2.74 & 1.10 & ND & 2 & 2 \\
\hline 9 & 2 & 0 & 2 & Tub & Diploid & 3.16 & 2.43 & 1.30 & 5.82 & 2 & 1 \\
\hline 21 & 2 & 0 & 2 & Tub & Diploid & 3.98 & 2.66 & 1.50 & 4.03 & 2 & ND \\
\hline 20 & 3 & 0 & 3 & Tub & Aneuploid & 4.13 & 4.00 & 1.03 & 7.11 & 2 & 2 \\
\hline 1 & 3 & 0 & 2 & Tub & Aneuploid & 4.44 & 3.71 & 1.20 & 9.00 & 2 & 2 \\
\hline 6 & 3 & 0 & 2 & Tub & Aneuploid & 4.54 & 3.55 & 1.28 & 0.30 & 2 & ND \\
\hline 29 & 3 & 0 & 2 & Tub & Aneuploid & 4.61 & 3.85 & 1.20 & 3.51 & 2 & 2 \\
\hline 4 & 4 & 0 & 2 & Tub & Aneuploid & 4.84 & 4.39 & 1.10 & 2.43 & 2 & 1 \\
\hline 14 & 3 & 1 & 2 & Tub & Aneuploid & 5.07 & 3.05 & 1.66 & 1.96 & 2 & ND \\
\hline 17 & 3 & 1 & 2 & Tub & Aneuploid & 11.54 & 8.32 & 1.39 & 21.56 & 2 & 2 \\
\hline 2 & 2 & 0 & 2 & Tub & Aneuploid & 13.35 & 13.29 & 1.00 & 12.30 & 2 & 0 \\
\hline 18 & 3 & 0 & 3 & Tub & Diploid & 2.42 & 2.19 & 1.11 & 7.62 & 3 & 3 \\
\hline 10 & 3 & 0 & 2 & Tub & Aneuploid & 2.89 & 2.62 & 1.10 & 9.13 & 3 & 2 \\
\hline 3 & 3 & 0 & 2 & Tub & Aneuploid & 3.33 & 2.69 & 1.24 & 2.55 & 3 & 3 \\
\hline 5 & 3 & 0 & 2 & Tub & Aneuploid & 3.40 & 3.87 & 0.88 & 23.59 & 3 & 4 \\
\hline 36 & 4 & 0 & 2 & Tub & Aneuploid & 5.15 & 5.02 & 1.03 & 3.23 & ND & 0 \\
\hline 26 & 3 & 2 & 2 & Tub & ND & ND & ND & ND & 19.84 & ND & ND \\
\hline \multicolumn{5}{|c|}{ B: Microsatellite instable } & \multicolumn{4}{|c|}{ FISH analysis } & $Q-R T-P C R$ analysis & \multicolumn{2}{|c|}{ IHC analysis } \\
\hline Case Id. & $p T$ & $p N$ & $G$ & Histology & Ploidy & Aurora A & CEP2O & Aurora A:CEP2O & Aurora A & Aurora A & Ki67 \\
\hline 13 & 3 & 1 & 2 & Tub & Diploid & 3.30 & 2.67 & 1.24 & 3.14 & 1 & ND \\
\hline 28 & 3 & 0 & 2 & Muc & Diploid & 2.70 & 2.15 & 1.26 & 0.83 & 2 & 3 \\
\hline 41 & 3 & $\mathrm{x}$ & 2 & Tub & Diploid & 2.70 & 2.62 & 1.03 & 10.13 & 2 & 3 \\
\hline 22 & 3 & 0 & 2 & Tub & Diploid & 3.06 & 2.36 & 1.30 & 8.00 & 2 & 1 \\
\hline 32 & 3 & 0 & 3 & Tub & Diploid & 3.32 & 3.14 & 1.06 & 0.57 & 2 & 1 \\
\hline 31 & 3 & 0 & 3 & Muc & Diploid & 4.30 & 3.66 & 1.17 & 1.01 & 2 & 1 \\
\hline 7 & 3 & 0 & 3 & Muc & Diploid & 2.55 & 2.55 & 1.00 & 4.03 & 3 & 1 \\
\hline 34 & 2 & 0 & 2 & Muc & Diploid & 2.81 & 2.27 & 1.24 & 2.14 & 3 & 3 \\
\hline 35 & 2 & 0 & 3 & Tub & Diploid & 2.93 & 2.70 & 1.09 & 3.51 & 3 & 3 \\
\hline 33 & 3 & 0 & 2 & Tub & Diploid & 3.89 & 2.90 & 1.34 & 0.38 & 3 & 3 \\
\hline 12 & 3 & 2 & 3 & Tub & ND & ND & ND & ND & 1.10 & ND & ND \\
\hline
\end{tabular}

Abbreviations: $\mathrm{G}=$ tumour grading; Tub = tubular carcinoma; Muc = mucinous carcinoma; $\mathrm{ND}=$ not determined/not detectable.

The table summarises case-specific clinicopathological parameters and experimental data for $\mathbf{A}=$ chromosomal instable $(n=31)$ and $\mathbf{B}=$ Microsatellite instable $(n=11)$ invasive carcinomas investigated in detail.

Note: fluorescence in situ hybridization (FISH) = mean signals per cell (Aurora A, CEP20) and ratio (Aurora A signals divided by CEP20 signals); Q-RT-PCR = relative mRNA expression; immunohistochemistry (IHC) = scores for Aurora A and Ki67 (see also Figure 1 for examples of IHC and Figure 3 for examples of FISH).

instable invasive carcinomas, the microsatellite instable invasive carcinomas had significantly more aurora A positive tumour cells, whilst there were no significant differences between chromosomal and microsatellite instable invasive carcinomas at the aurora A mRNA level. Aurora A expression and associated regulatory mechanisms of post-transcrip- tional modifications and/or protein stability may be distinct in chromosomal and microsatellite instable invasive carcinomas, especially in view of aurora $A$ gene amplification in chromosomal instable invasive carcinomas. However, more importantly, we asked whether this frequently described aurora A 'over' expression ${ }^{40-44}$ is regulated by tumour cell 

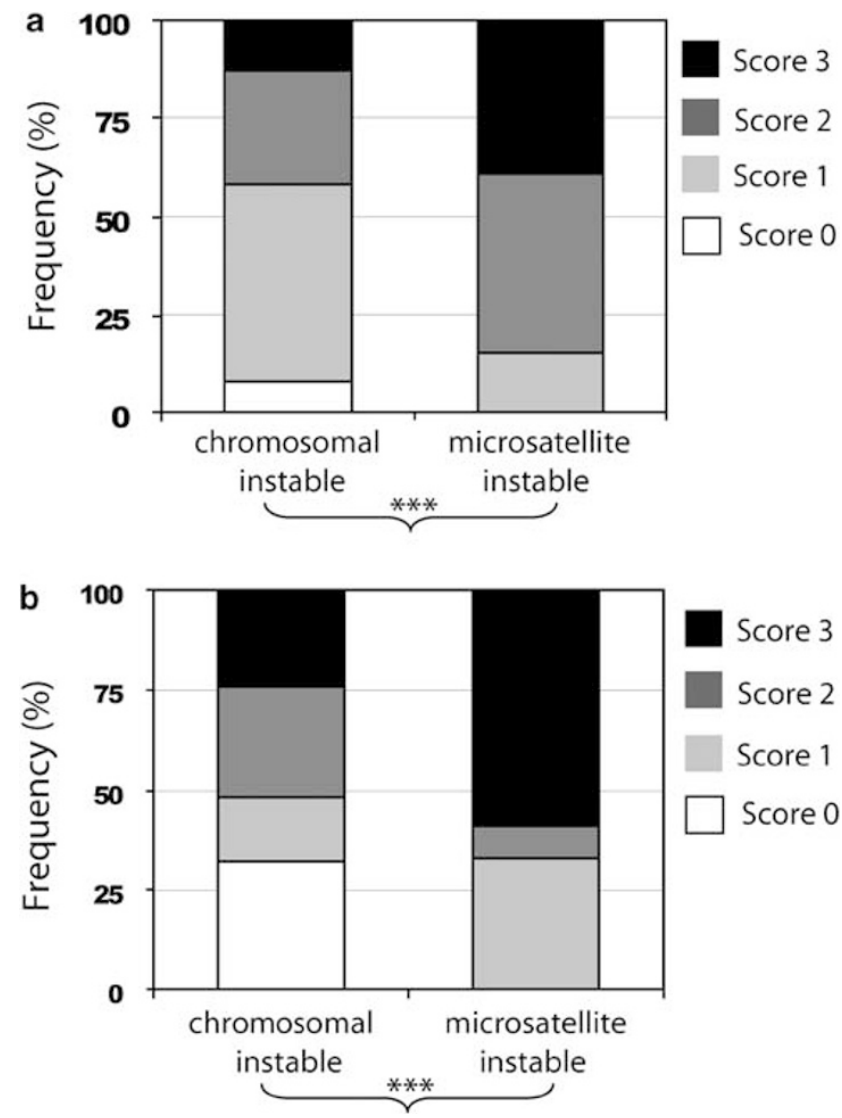

Figure 4 Comparison of aurora A protein expression and tumour cell proliferation in chromosomal and microsatellite instable sporadic colorectal cancers. The figure summarizes results of aurora A- (a) and Ki-67- (b) specific immunohistochemistry in chromosomal and microsatellite instable invasive carcinomas. Note that high aurora A- and Ki67-scores were significantly more frequent in microsatellite instable as compared with chromosomal instable invasive carcinomas (marked by brackets and ***; $P$ values are given in the main text).

proliferation, especially since aurora $\mathrm{A}$ is an essential part of the cell cycle machinery ${ }^{49,50}$ and since microsatellite instable colorectal cancers show an increased rate of tumour cell proliferation. ${ }^{58}$ This increase in proliferation may be accompanied by increased aurora A protein activity and/or stability explaining why only aurora A protein, but not mRNA levels were different between chromosomal and microsatellite instable invasive carcinomas. Indeed, also in our series of sporadic colorectal cancers microsatellite instable invasive carcinomas exhibited a higher frequency of Ki67 positive tumour cells, respective increased tumour cell proliferation on comparison to chromosomal instable invasive carcinomas. Moreover, we showed that the presence of aurora A positive tumour cells was significantly correlated with tumour cell proliferation. Taken together, we reason that aurora A (over)expression is tightly associated and regulated by tumour cell proliferation in microsatellite instable sporadic colorectal cancers, whereas an additional level of (de)regulation of aurora A (over)- expression occurs at the DNA level in chromosomal instable sporadic colorectal cancers. In fact, strong aurora A expression can be seen in both microsatellite and chromosomal instable invasive carcinomas-only in a different frequency of tumour cells. This might introduce a measurements bias of aurora A levels obtained from whole populations of colorectal cancer cell lines and/or entire tumour extracts. ${ }^{41,48}$

Further to the difference of aurora A expression and regulation at the level of specific molecular subtypes of colorectal cancer cells, the heterogeneity of aurora A within individual colorectal cancers requires further attention. In particular, it has been recently shown that aurora A is functionally linked with signalling mechanisms of cell polarity, ${ }^{65}$ suggesting that aurora A may also play a role at the invasive tumour edge. Thus, further studies, for example, clinical phase trials of aurora inhibitors, should also include early/prospective in situ analyses of individual tumour cells in tissue specimens.

Clearly, as suggested before, ${ }^{44,66,67}$ strong aurora A expression alone does not suffice to induce chromosomal instability and/or aneuploidy, as observed in this study for diploid microsatellite instable sporadic colorectal cancers. In contrast, the close association of-and rather moderate-aurora A expression with aneuploidy in chromosomal instable sporadic colorectal cancers points to the involvement of e.g. additional defects of checkpoint controls. Thus, within the chromosomal instable invasive carcinomas it might be those with defective p53 signalling ${ }^{66,67}$ or other checkpoint controls ${ }^{44}$ in which-also marginally-elevated aurora A expression is able to trigger overt aneuploidy. In this case, the effect of aurora (-A) inhibitors may be less efficient than in aurora A expressing tumour cells without additional defective checkpoint controls. In addition, it is reasonable that the activation status of aurora A, controlled by phosphorylation as well as protein stability ${ }^{64}$, may introduce a further functional level affecting successful aurora (-A) inhibition and tumour cell death. ${ }^{68}$ In this context, functional investigations of inactive/active aurora A protein levels as well as other centrosomal and chromosomal passenger complex ${ }^{13-21}$ proteins in chromosomal and microsatellite instable colorectal tumour cell lines with specific reference to their interaction with the $\mathrm{p} 53^{66}$ and adenomatosis polyposis coli ${ }^{24,25}$ pathways, will certainly be a worthwhile effort and are subject of our ongoing in vitro investigations.

Irrespective of the potential differential therapeutic response of chromosomal and microsatellite instable colorectal cancers to aurora A inhibitors, this study shows that between 42 and $85 \%$ of sporadic colorectal cancer cases may be considered for novel, aurora-targeted therapies. ${ }^{35-38}$ Whereas previous studies have analysed the antitumoural effect of aurora inhibitors, targeting both aurora A and aurora B, in a recent study, Manfredi et a $l^{69}$ have 
evaluated the antitumour activity of an aurora A specific inhibitor, which has also entered phase I clinical trials for solid tumours. Specifically, the authors had included three colorectal cancer cell lines in their study, two of which are microsatellite instable (HCT-116, DLD-1) and one of which is chromosomal instable (SW480). In HCT116 cells, the mechanism of action of the tested compound was a reduction of aurora A activity, but not aurora A degradation or down-regulation. The reduced phosphorylation of aurora A led to cell cycle progression delay and tumour cell growth inhibition in vitro as well as to a high efficacy for growth inhibition of in vivo HCT116 xenografts. This is in accordance with our data on aurora A expression and deregulation in microsatellite instable sporadic colorectal cancers. A detailed comparison of the effects of this aurora A inhibitor in chromosomal and microsatellite instable colorectal cancer cell lines, potentially also showing differences in mitotic checkpoint controls, ${ }^{44,66,67}$ will be a valuable experimental setup before further clinical testing.

Besides, aurora A expression in colorectal cancers may also be a valuable predictive marker for current therapeutic strategies, as shown for other epithelial tumours ${ }^{53,67,70,71}$ or in the neoadjuvant setting of rectal cancer. ${ }^{72}$ In fact, we found a weak association of high aurora A protein expression with nodenegative colorectal cancer cases. One explanation may be that during migration (tumour) cells downregulate their proliferative activity and hence aurora A expression. Therefore, the high proliferation rate and/or presence of high numbers of aurora A positive cells may reflect a non-migratory phenotype of colorectal cancer, ie the node-negative cases. Clearly, further studies need to address the prognostic and predictive impact of aurora A expression in view of clinical UICC stages.

In summary, this study further supports a role of aurora A in the carcinogenesis of sporadic colorectal cancers. Moreover, it demonstrates that in a minority of predominantly microsatellite instable sporadic colorectal cancers, the presence of aurora A positive tumour cells is merely reflecting tumour cell proliferation. In contrast, the large majority of chromosomal instable sporadic colorectal cancers shows additional (de)regulation of aurora $\mathrm{A}$ by gene amplification and concomitant tumour cell aneuploidy. Thus, sporadic colorectal cancers exhibit different mechanism of aurora A regulation and this may impact the efficacy of aurora-targeted therapies and/or may influence the associated therapeutic protocols.

\section{Acknowledgements}

The authors acknowledge the excellent laboratory work of Jasmine Roth and Anja Schöpflin. In addition, SL and MW also greatly acknowledge long term, generous funding of the Mushett Family Foundation (Chester, New Jersey, USA). MD acknowledges the support of the German Academic Exchange Service (DAAD).

\section{Disclosure/conflict of interest}

This study has been funded in parts by the Medical Faculty, University Medical Center Freiburg (grant \#LASS203/03 to SL and MW), by the German Research Foundation (DFG, grant \#LA 1290/3-1 to SL and MW) and by a long term research grant to SL and MW from the Mushett Family Foundation (Chester, New Jersey, US). MD was funded by the German Academic Exchange Service (DAAD).

\section{References}

1 Fearon E, Vogelstein B. A genetic model for colorectal tumourigenesis. Cell 1990;61:759-767.

2 Jass JR. Classification of colorectal cancer based on correlation of clinical, morphological and molecular features. Histopathology 2007;50:113-130.

3 Ogino S, Goel A. Molecular classification and correlates in colorectal cancer. J Mol Diagn 2008;10:13-27.

4 Lengauer C, Kinzler K, Vogelstein B. Genetic instability in colorectal cancers. Nature 1997;386:623-627.

5 Diep CB, Kleivi K, Ribeiro FR, et al. The order of genetic events associated with colorectal cancer progression inferred from meta-analysis of copy number changes. Genes Chromosomes Cancer 2006;45:31-41.

6 Meijer GA, Hermsen MA, Baak JP, et al. Progression from colorectal adenoma to carcinoma is associated with non-random chromosomal gains as detected by comparative genomic hybridisation. J Clin Pathol 1998;51:901-909.

7 Popat S, Hubner R, Houlston RS. Systematic review of microsatellite instability and colorectal cancer prognosis. J Clin Oncol 2005;23:609-618.

8 Söreide K, Janssen EA, Söiland H, et al. Microsatellite instability in colorectal cancer. Br J Surg 2006;93: 395-406.

9 Ghadimi BM, Sackett DL, Difilippantonio MJ, et al. Centrosome amplification and instability occurs exclusively in aneuploid, but not in diploid colorectal cancer cell lines, and correlates with numerical chromosomal aberrations. Genes Chromosomes Cancer 2000;27:183-190.

10 Sugai T, Takahashi H, Habano W, et al. Analysis of genetic alterations, classified according to their DNA ploidy pattern, in the progression of colorectal adenomas and early colorectal carcinomas. J Pathol 2003;200:168-176.

11 Klein A, Zang KD, Steudel WI, et al. Different mechanisms of mitotic instability in cancer cell lines. Int J Oncol 2006;29:1389-1396.

12 Pantic M, Zimmermann S, El Daly H, et al. Telomere dysfunction and loss of p53 cooperate in defective mitotic segregation of chromosomes in cancer cells. Oncogene 2006;25:4413-4420.

13 Jallepalli P, Lengauer C. Chromosome segregation and cancer: cutting through the mystery. Nat Rev Cancer 2001;1:109-117. 
14 Adams RR, Carmena M, Earnshaw WC. Chromosomal passengers and the (aurora) ABCs of mitosis. Trends Cell Biol 2001;11:49-54.

15 Terada Y. Role of chromosomal passenger complex in chromosome segregation and cytokinesis. Cell Struct Funct 2001;26:653-657.

16 Nguyen HG, Ravid K. Tetraploidy/aneuploidy and stem cells in cancer promotion: the role of chromosome passenger proteins. J Cell Physiol 2006;208: 12-22.

17 Ruchaud S, Carmena M, Earnshaw WC. Chromosomal passengers: conducting cell division. Nat Rev Mol Cell Biol 2007;8:798-812.

18 Vader G, Maia AF, Lens SM. The chromosomal passenger complex and the spindle assembly checkpoint: kinetochore-microtubule error correction and beyond. Cell Div 2008;3:10.

19 Musacchio A, Salmon ED. The spindle-assembly checkpoint in space and time. Nat Rev Mol Cell Biol 2007;8:379-393.

20 Bharadwaj $\mathrm{R}, \mathrm{Yu} \mathrm{H}$. The spindle checkpoint, aneuploidy, and cancer. Oncogene 2004;23:2016-2027.

21 Decordier I, Cundari E, Kirsch-Volders M. Mitotic checkpoints and the maintenance of the chromosome karyotype. Mutat Res 2008;651:3-13.

22 Fearnhead NS, Britton MP, Bodmer WF. The ABC of APC. Hum Mol Genet 2001;10:721-733.

23 Narayan S, Roy D. Role of APC and DNA mismatch repair genes in the development of colorectal cancers. Mol Cancer 2003;2:41.

24 Fodde R, Kuipers J, Rosenberg C, et al. Mutations in the APC tumour suppressor gene cause chromosomal instability. Nat Cell Biol 2001;3:433-438.

25 Kaplan KB, Burds AA, Swedlow JR, et al. A role for the Adenomatous Polyposis Coli protein in chromosome segregation. Nat Cell Biol 2001;3:429-432.

26 Hanson CA, Miller JR. Non-traditional roles for the Adenomatous Polyposis Coli (APC) tumor suppressor protein. Gene 2005;361:1-12.

27 Aoki K, Taketo MM. Adenomatous polyposis coli (APC): a multi-functional tumor suppressor gene. J Cell Sci 2007;120:3327-3335.

28 Caldwell CM, Green RA, Kaplan KB. APC mutations lead to cytokinetic failures in vitro and tetraploid genotypes in Min mice. J Cell Biol 2007;178: 1109-1120.

29 Nigg E. Centrosome aberrations: cause or consequence of cancer progression? Nat Rev Cancer 2002;2:815-825.

30 Fukasawa K. Oncogenes and tumour suppressors take on centrosomes. Nat Rev Cancer 2007;7:911-924.

31 Giet R, Petretti C, Prigent C. Aurora kinases, aneuploidy and cancer, a coincidence or a real link? Trends Cell Biol 2005;15:241-250.

32 Marumoto T, Zhang D, Saya H. Aurora A-a guardian of poles. Nat Rev Cancer 2005;5:42-50.

33 Barr AR, Gergely F. Aurora A: the maker and breaker of spindle poles. J Cell Sci 2007;120:2987-2996.

34 Keen N, Taylor S. Aurora-kinase inhibitors as anticancer agents. Nat Rev Cancer 2004;4:927-936.

35 Andrews PD. Aurora kinases: shining lights on the therapeutic horizon? Oncogene 2005;24:5005-5015.

36 Carvajal RD, Tse A, Schwartz GK. Aurora kinases: new targets for cancer therapy. Clin Cancer Res 2006;12:6869-6875.

37 Agnese V, Bazan V, Fiorentino FP, et al. The role of Aurora A inhibitors in cancer therapy. Ann Oncol 2007;18:vi47-vi52.
38 Gautschi O, Heighway J, Mack PC, et al. Aurora kinases as anticancer drug targets. Clin Cancer Res 2008;14:1639-1648.

39 Zhou H, Kuang J, Zhong L, et al. Tumour amplified kinase STK15/BTAK induces centrosome amplification, aneuploidy and transformation. Nat Genet 1998;20:189-193.

40 Bischoff JR, Anderson L, Zhu Y, et al. A homologue of Drosophila aurora kinase is oncogenic and amplified in human colorectal cancers. EMBO J 1998;17: 3052-3065.

41 Nishida N, Nagasaka T, Kashiwagi K, et al. High copy amplification of the Aurora A gene is associated with chromosomal instability phenotype in human colorectal cancers. Cancer Biol Ther 2007;6:525-533.

42 Takahashi T, Futamura M, Yoshimi N, et al. Centrosomal kinases, HsAIRK1 and HsAIRK3, are overexpressed in primary colorectal cancers. Jpn J Cancer Res 2000;91:1007-1014.

43 Lam AK, Ong K, Ho YH. Aurora kinase expression in colorectal adenocarcinoma: correlations with clinicopathological features, p16 expression, and telomerase activity. Hum Pathol 2008;39:599-604.

44 Burum-Auensen E, DeAngelis PM, Schjølberg AR, et al. Reduced level of the spindle checkpoint protein BUB1B is associated with aneuploidy in colorectal cancers. Cell Prolif 2008;41:645-659.

45 Gerlach U, Kayser G, Walch A, et al. Centrosome-, chromosomal-passenger- and cell-cycle-associated mRNAs are differentially regulated in the development of sporadic colorectal cancer. J Pathol 2006;208: $462-472$.

46 Lassmann S, Weis R, Makowiec F, et al. Array CGH identifies distinct DNA copy number profiles of oncogenes and tumoursuppressorgenes in chromosomal- and microsatellite-unstable sporadic colorectal carcinomas. J Mol Med 2007;85:289-300.

47 Lassmann S, Kreutz C, Schoepflin A, et al. A novel approach for reliable microarray analysis of microdissected tumor cells from formalin-fixed and paraffinembedded colorectal cancer resection specimens. J Mol Med 2009;87:211-224.

48 Lentini L, Amato A, Schillaci T, et al. Simultaneous Aurora A/STK15 overexpression and centrosome amplification induce chromosomal instability in tumour cells with a MIN phenotype. BMC Cancer 2007; 7:212.

49 Kimura M, Kotani S, Hattori T, et al. Cell cycledependent expression and spindle pole localization of a novel human protein kinase, Aik, related to Aurora of Drosophila and yeast Ipl1. J Biol Chem 1997;272:13766-13771.

50 Marumoto T, Hirota T, Morisaki T, et al. Roles of Aurora A kinase in mitotic entry and G2 checkpoint in mammalian cells. Genes Cells 2002;7:1173-1182.

51 Hamilton S, Aaltonen L. Pathology and genetics of tumors of the digestive system. WHO Classification of Tumors. IARC Press: Lyon, 2000.

52 Sobin LH, Wittekind C, (eds). TNM Classification of malignant tumours. UICC, 6th edn. Wiley Liss Inc: New York, 2002.

53 Lassmann S, Shen Y, Jütting U, et al. Predictive value of Aurora A/STK15 expression for late stage epithelial ovarian cancer patients treated by adjuvant chemotherapy. Clin Cancer Res 2007;13:4083-4091.

54 Livak KJ, Schmittgen TD. Analysis of relative gene expression data using real-time quantitative PCR and 
the 2(-Delta Delta C(T)) Method. Methods 2001;25: 402-408.

55 Gerdes J, Lemke H, Baisch H, et al. Cell cycle analysis of a cell proliferation-associated human nuclear antigen defined by the monoclonal antibody Ki-67. J Immunol 1984;133:1710-1715.

56 Jubb AM, Landon TH, Burwick J, et al. Quantitative analysis of colorectal tissue microarrays by immunofluorescence and in situ hybridization. J Pathol 2003;200:577-588.

57 Greenman J, Ashman JN, Brankin V, et al. Multiple cell populations in colorectal carcinomas: analysis by 3colour fluorescence in situ hybridization. Int J Oncol 1998;12:75-80.

58 Michael-Robinson JM, Reid LE, Purdie DM, et al. Proliferation, apoptosis, and survival in high-level microsatellite instability sporadic colorectal cancer. Clin Cancer Res 2001;7:2347-2356.

59 Tong T, Zhong Y, Kong J, et al. Overexpression of Aurora A contributes to malignant development of human esophageal squamous cell carcinoma. Clin Cancer Res 2004;10:7304-7310.

60 Sakakura C, Hagiwara A, Yasuoka R, et al. Tumour-amplified kinase BTAK is amplified and overexpressed in gastric cancers with possible involvement in aneuploid formation. Br J Cancer 2001;84: 824-831.

61 Gritsko TM, Coppola D, Paciga JE, et al. Activation and overexpression of centrosome kinase BTAK/Aurora A in human ovarian cancer. Clin Cancer Res 2003;9: 1420-1426.

62 Miyoshi Y, Iwao K, Egawa C, et al. Association of centrosomal kinase STK15/BTAK mRNA expression with chromosomal instability in human breast cancers. Int J Cancer 2001;92:370-373.

63 Katayama H, Sasai K, Czerniak BA, et al. Aurora A kinase phosphorylation of Aurora A kinase interacting protein (AIP) and stabilization of the enzyme-substrate complex. J Cell Biochem 2007;102:1318-1331.

64 Lim SK, Gopalan G. Aurora A kinase interacting protein 1 (AURORA AIP1) promotes Aurora A degradation through an alternative ubiquitin-independent pathway. Biochem J 2007;403:119-127.

65 Wirtz-Peitz F, Nishimura T, Knoblich JA. Linking cell cycle to asymmetric division: Aurora A phosphorylates the Par complex to regulate Numb localization. Cell 2008;135:161-173.

66 Meraldi P, Honda R, Nigg EA. Aurora A overexpression reveals tetraploidization as a major route to centrosome amplification in p53-/- cells. EMBO J 2002;21:483-492.

67 Yang H, He L, Kruk P, et al. Aurora A induces cell survival and chemoresistance by activation of Akt through a p53-dependent manner in ovarian cancer cells. Int J Cancer 2006;119:2304-2312.

68 Littlepage LE, Wu H, Andresson T, et al. Identification of phosphorylated residues that affect the activity of the mitotic kinase Aurora A. Proc Natl Acad Sci USA 2002;99:15440-15445.

69 Manfredi MG, Ecsedy JA, Meetze KA, et al. Antitumor activity of MLN8054, an orally active small-molecule inhibitor of Aurora A kinase. Proc Natl Acad Sci USA 2007;104:4106-4111.

70 Anand S, Penrhyn-Lowe S, Venkitaraman AR. AURORA A amplification overrides the mitotic spindle assembly checkpoint, inducing resistance to Taxol. Cancer Cell 2003;3:51-62.

71 Hata T, Furukawa T, Sunamura M, et al. RNA interference targeting aurora kinase a suppresses tumour growth and enhances the taxane chemosensitivity in human pancreatic cancer cells. Cancer Res 2005;5:2899-2905.

72 Guan Z, Wang XR, Zhu XF, et al. Aurora A, a negative prognostic marker, increases migration and decreases radiosensitivity in cancer cells. Cancer Res 2007;67:10436-10444. 